\title{
Evaluation of the Japanese eel fishery in the lower reaches of the Kao-Ping River, southwestern Taiwan using a per-recruit analysis
}

\author{
Yu-Jia Lin ${ }^{\mathrm{a}}$, Yi-Jay Chang ${ }^{\mathrm{b}}$, Chi-Lu Sun ${ }^{\mathrm{b}}$, Wann-Nian Tzeng ${ }^{\mathrm{a}, \mathrm{c}, *}$ \\ a Institute of Fisheries Science, National Taiwan University (NTU), Taipei, Taiwan \\ ${ }^{\mathrm{b}}$ Institute of Oceanography, NTU, Taiwan \\ ${ }^{\mathrm{c}}$ Department of Life Science, NTU, Taiwan
}

\section{A R T I C L E I N F O}

\section{Article history:}

Received 14 July 2009

Received in revised form 31 August 2010

Accepted 31 August 2010

\section{Keywords:}

Anguilla japonica

Per-recruit analysis

Overfishing

Uncertainty

\begin{abstract}
A B S T R A T
Yield-per-recruit (YPR) and spawning stock biomass-per-recruit (SPR) models were used to investigate the impact of fisheries on the yellow and silver eels of the local stock of Japanese eel (Anguilla japonica) in the Kao-Ping River (southwestern Taiwan). The current fishery status and uncertainty of biological reference points (e.g., $F_{\max }, F_{0.1}, F_{40 \%}$, and $F_{50 \%}$ ) were assessed using Monte Carlo simulation. Probabilities of the current fishing mortality rate for yellow and silver eels $\left(F_{\text {cur }}\right)$ being higher than $F_{\max }$ ranged $15-20 \%$, and being higher than $F_{0.1}$ ranged 58-66\%. The probabilities of $F_{\text {cur }}$ being higher than $F_{40 \%}$ and $F_{50 \%}$ ranged 26-93\% and 73-99\%, respectively. The Japanese eel in the lower reaches of the Kao-Ping River appeared to be fully exploited in terms of YPR. This local stock is also subject to a high risk of recruitment overfishing because the contribution of the SPR of the local stock to the entire Japanese eel stock is possibly below a minimal acceptable level (40\%). Estimates of $F_{0.1}$ and $F_{\max }$, and to a lesser extent those of $F_{40 \%}$ and $F_{50 \%}$, were relatively robust, but estimates of the maximal YPR and SPR at $F_{\text {cur }}$ were highly sensitive to the uncertainty of the input parameters.
\end{abstract}

(c) 2010 Elsevier B.V. All rights reserved.

\section{Introduction}

Japanese eel (Anguilla japonica, Temminck and Schlegel, 1847) is a catadromous fish, widely distributed in Taiwan, China, Korea, and Japan (Tesch, 2003). The population of this eel is considered to be weakly structured between south and north of the distribution (Tseng et al., 2006) or to be panmictic (Sang et al., 1994; Han et al., 2010). A. japonica is the most abundant among the 4 species found in Taiwan (Tzeng, 1982; Tzeng and Tabeta, 1983; Teng et al., 2009), comprising approx. 90\% of the total eel catch in the wild (Tzeng et al., 1995; Tzeng and Chang, 2001).

Japanese eel are harvested at different stages (glass eel, elver, and yellow and silver eels) by different fisheries in Taiwan. Glass eels are caught in river mouths during their upstream migration by fishermen using set-nets, fyke-nets, and traps. Yellow and silver eels are mainly harvested in the lower reaches of rivers. The Kao-Ping River contains the largest eel fishery for yellow and silver eels in Taiwan (Lin and Tzeng, 2008). Prices of wild-caught eels are higher than those from aquaculture, consequently encouraging the eel fishery (Chang and Tzeng, 1990). Yellow and silver eels are

\footnotetext{
* Corresponding author. Present address: Department of Environmental Biology and Fisheries Science, National Taiwan Ocean University, Keelung, Taiwan. Tel.: +8862 33662887; fax: +886223639570.

E-mail address: wnt@ntu.edu.tw (W.-N. Tzeng).
}

by-catch in shrimp nets, which have been widely used for targeting shrimp in Taiwan since 2003 (Lin and Tzeng, 2008). The shrimp net is highly efficient for harvesting eels of $>200 \mathrm{~mm}$ in total length.

The yellow and silver eel fisheries in Taiwan are unregulated. The elevated exploitation of both yellow and silver eels is likely to lead to reduced local eel stocks in Taiwan and result in insufficient contributions to the total stock (Lin, 2009). Furthermore, eel culture still depends on wild-caught glass eels. Despite the importance of the Japanese eels to the eel fisheries and aquaculture, no quantitative stock assessment has been conducted to date.

Compared to an assembly of different fisheries exploiting a single stock, a small-scale eel fishery such as the Japanese eel fishery in the Kao-Ping River is generally less difficult to assess (Dekker, 2000). For a smaller-scale eel fishery, it is also easier to obtain biological data and implement adequate monitoring plans. Perrecruit analysis (i.e., yield-per-recruit (YPR) and spawning stock biomass-per-recruit (SPR) analyses) is often recommended as a rapid assessment tool for a small-scale fishery (Kruse et al., 2005).

In this study, a per-recruit analysis was used to assess the status of the Kao-Ping River Japanese eel fishery and evaluate the effectiveness of two possible management regulations (minimum and maximum legal lengths) that are commonly used for other eel fisheries (e.g., eel fisheries in New Zealand, Hoyle and Jellyman, 2002). A Monte Carlo simulation study was conducted to evaluate how the uncertainty of input parameters might influence estimates of fishing mortality-based biological reference points and their levels of 
uncertainty. The risk of biological overfishing of this local eel stock was also evaluated, using a stochastic decision-making framework (Helser et al., 2001; Chen and Wilson, 2002; Chang et al., 2009).

\section{Materials and methods}

\subsection{Per-recruit analysis}

YPR and SPR analyses of Japanese eel in the study area were conducted using the methodology described in Quinn and Deriso (1999):

$$
\begin{aligned}
Y P R= & \int_{t_{r}}^{t_{\max }} F N(u) W(u) d u=e^{-M\left(t_{c}-t_{r}\right)} F \\
& \times \int_{t_{c}}^{t_{\max }} e^{-(F+M)\left(u-t_{r}\right)} a\left\{L_{\infty}\left[1-e^{-K\left(u-t_{0}\right)}\right]\right\}^{b} d u \text { and } \\
S P R= & \int_{t_{r}}^{t_{\max }}\{N(u) W(u) S(u)\} d u \\
= & \int_{t_{r}}^{t_{c}}\left\{e^{-M\left(u-t_{r}\right)} a\left\{L_{\infty}\left[1-e^{-K\left(u-t_{0}\right)}\right]\right\}^{b}\right. \\
& \times \frac{1}{\left.1+e^{\left[\beta_{0}+\beta_{1} L_{\infty}\left(1-e^{-K\left(u-t_{0}\right)}\right)\right]}\right\} d u} \\
+ & \int_{t_{c}}^{t_{\max }}\left\{e^{-(F+M)\left(u-t_{r}\right)} a\left\{L_{\infty}\left[1-e^{-K\left(u-t_{0}\right)}\right]\right\}^{b}\right. \\
& \times \frac{1}{\left.1+e^{\left[\beta_{0}+\beta_{1} L_{\infty}\left(1-e^{-K\left(u-t_{0}\right)}\right)\right]}\right\} d u}
\end{aligned}
$$

where the population growth in number is assumed to be exponential, the weight-length relationship to be allometric, and the length-age relationship to be a von Bertalanffy growth function. The maturation process is defined as the silvering process and was assumed to follow a logistic curve. Symbols are defined in the Appendix A. The selection curve of the shrimp net is assumed to be "knife-edged", with eels of $>200 \mathrm{~mm}$ in length being fully vulnerable (Lin and Tzeng, 2008).

Sexes were pooled in the YPR analysis because eel fishermen do not currently separate females from males at the time of harvest, i.e., the fishing mortality $(F)$ cannot be separately specified for males and females. However, female biomass might be more closely associated with egg production, and females dominated $(>70 \%)$ the studied stock (Han and Tzeng, 2006). Females also grow and mature differently from males (Han et al., 2003; Lin and Tzeng, 2009b), and therefore the SPR analyses were separately carried out by sex.

Four fishing mortality-based biological reference points $\left(F_{\mathrm{BRP}}\right)$ of $F_{\text {max }}, F_{0.1}, F_{40 \%}$, and $F_{50 \%}$, were estimated using per-recruit analysis. $F_{\max }$ and $F_{0.1}$ are defined as the fishing mortality rates corresponding to the maximum value of the YPR function and the fishing mortality at which the slope of the YPR function is $10 \%$ of that at $F=0$, respectively (Deriso, 1987). $F_{40 \%}$ and $F_{50 \%}$ are fishing mortality rates respectively corresponding to $40 \%$ and $50 \%$ of the spawning stock biomass-per-recruit at unfished levels (Goodyear, 1993). Although the International Council for the Exploitation of the Seas (ICES, 2002) suggests $F_{30 \%}$ and $F_{50 \%}$ as the limit and precautionary reference points for European eel (A. anguilla), a more-conservative limit level of $40 \%$ of the SPR was chosen given the variability in glass eel recruitment in Taiwan (Tzeng, 2006), as suggested by Clark $(1993,2002)$. Key YPR and SPR values for evaluating a fishery's status, namely the maximal YPR ( $\left.Y P R_{\max }\right)$, the SPR in the absence of exploitation of yellow and silver eels $\left(S P R_{0}\right)$ and at current fishing mortality $\left(S P R_{F c u r}\right)$, and the relative $S P R\left(\% S P R=S P R_{F c u r} \times S P R_{0}{ }^{-1} \times 100 \%\right)$, were also calculated. The integrals of the YPR and SPR functions were computed using the $R$
Table 1

\begin{tabular}{|c|c|c|c|}
\hline Formula & Parameter & Female & Male \\
\hline \multicolumn{4}{|l|}{ Length-weight relationship } \\
\hline \multirow{2}{*}{$W_{t}=a L_{t}^{b} e^{\varepsilon_{L W}}$} & $a$ & $4.56 \times 10^{-8}$ & $1.61 \times 10^{-7}$ \\
\hline & $b$ & 3.55 & 3.34 \\
\hline$\varepsilon_{L W} \sim N\left(0, \sigma_{L W}^{2}\right)$ & $\sigma_{L W}^{2}$ & $3.93 \times 10^{-2}$ & $2.74 \times 10^{-2}$ \\
\hline \multicolumn{4}{|l|}{ Growth } \\
\hline \multirow{3}{*}{$L_{t}=L_{\infty}\left[1-e-K\left(t-t_{0}\right)\right] e^{\varepsilon_{G R}}$} & $L_{\infty}(\mathrm{mm})$ & 1023.7 & 758.7 \\
\hline & $K\left(\mathrm{yr}^{-1}\right)$ & 0.118 & 0.169 \\
\hline & $t_{0}(\mathrm{yr})$ & \multicolumn{2}{|c|}{-0.69} \\
\hline$\varepsilon_{G R} \sim N\left(0, \sigma_{G R}^{2}\right)$ & $\sigma_{G R}^{2}$ & \multicolumn{2}{|c|}{$3.10 \times 10^{-2}$} \\
\hline \multicolumn{4}{|l|}{$\begin{array}{l}\text { Mortality of yellow } \\
\text { and silver eels }\end{array}$} \\
\hline \multirow[t]{5}{*}{$N_{t}=N_{r} e^{-\left[\left(F_{\text {cur }}\right)+\left(M+\varepsilon_{M}\right)\right]\left(t-t_{r}\right)}$} & $F\left(\mathrm{yr}^{-1}\right)$ & \multicolumn{2}{|c|}{0.120} \\
\hline & $\sigma_{F_{c u r}}^{2}$ & \multicolumn{2}{|c|}{$1.06 \times 10^{-3}$} \\
\hline & $M\left(\mathrm{yr}^{-1}\right)$ & \multicolumn{2}{|c|}{0.177} \\
\hline & $\sigma_{M}^{2}$ & \multicolumn{2}{|c|}{$1.98 \times 10^{-5}$} \\
\hline & $\rho_{G R, M}^{M}$ & \multicolumn{2}{|c|}{0.8} \\
\hline \multicolumn{4}{|l|}{ Maturation (silvering) } \\
\hline \multirow{4}{*}{$S_{t}=\frac{1}{1+e^{\left[\left(\beta_{0}+\varepsilon_{\beta_{0}}\right)+L_{t}\left(\beta_{1}+\varepsilon_{\beta_{1}}\right)\right]}}$} & $\beta_{0}$ & -13.31 & -8.92 \\
\hline & $\sigma_{\beta_{0}}^{2}$ & 1.36 & 4.08 \\
\hline & $\beta_{1}\left(\mathrm{~mm}^{-1}\right)$ & $2.15 \times 10^{-2}$ & $1.75 \times 10^{-2}$ \\
\hline & $\sigma_{\beta_{1}}^{2}$ & $4.04 \times 10^{-6}$ & $1.60 \times 10^{-5}$ \\
\hline$\varepsilon_{\beta_{0}} \sim N\left(0, \sigma_{\beta_{0}}^{2}\right), \varepsilon_{\beta_{1}} \sim N\left(0, \sigma_{\beta_{1}}^{2}\right)$ & $\rho_{\beta_{0}, \beta_{1}}$ & \multicolumn{2}{|c|}{-0.9} \\
\hline Maximum observed length (mm) & & 880 & 700 \\
\hline Maximum age $\left(t_{\max }, \mathrm{yr}\right)$ & & 15.95 & 14.45 \\
\hline Length at recruitment $\left(L_{r}, \mathrm{~mm}\right)$ & & \multicolumn{2}{|c|}{55} \\
\hline Age at recruitment $\left(t_{r}, \mathrm{yr}\right)$ & & \multicolumn{2}{|c|}{0.489} \\
\hline Length at first capture $\left(L_{c}, \mathrm{~mm}\right)$ & & \multicolumn{2}{|c|}{200} \\
\hline
\end{tabular}

Formulae, parameter estimates, and corresponding variances $\left(\sigma^{2}\right)$ of sex-specific length-weight relationships, von Bertalanffy growth functions, mortality rates, and maturation parameters for Anguilla japonica. $W_{t}, L_{t}, N_{t}$, and $S_{t}$ are the weight, length, population size, and proportion of silver eels in the population at time $t . N_{r}$ is the population size recruiting to the fishing ground. $\rho_{X, Y}$ is the correlation between variables $X$ and $Y$.

function, integrate (vers. 2.8.1, Owen, 2006). $F_{\mathrm{BRP}}$ and key YPR and SPR values were calculated using Newton's method in $R$.

Two possible management regulations for the management of the eel fishery, minimum $\left(L_{\min }\right)$ and maximum $\left(L_{\max }\right)$ legal lengths, were incorporated in the YPR and SPR models by setting $F$ equal to 0 when the total length of a fish was $<L_{\min }$ or $>L_{\max }$. The minimum length of eels caught by the current unregulated fishery is $200 \mathrm{~mm}$ (Lin and Tzeng, 2008), and thus $L_{\min }$ was set to 200-700 $\mathrm{mm}$ for both sexes. $L_{\max }$ decreased from 800 to $400 \mathrm{~mm}$ in females and 700 to $300 \mathrm{~mm}$ in males to accommodate different asymptotic $\left(L_{\infty}\right)$ and maximum observed lengths between the sexes (Table 1$)$.

\subsection{Incorporation of uncertainty in the parameter estimation}

The above per-recruit analysis is deterministic and ignores parameter uncertainty. Therefore, a Monte Carlo simulation approach was used to account for parameter uncertainty (cf. Chen and Wilson, 2002; Grabowski and Chen, 2004; Chang et al., 2009). To quantify the uncertainty of the parameters, log-normal multiplicative errors were added to the weight-atlength and length-at-age relationships: $W^{\prime}=a L^{b} e^{\varepsilon_{L W}}$ and $L_{t}^{\prime} L_{\infty}[1-$ $\left.e^{-K\left(t-t_{0}\right)}\right] e^{\varepsilon_{G R}}$, respectively. The uncertainty in $M$ and the maturation parameters $\left(\beta_{0}\right.$ and $\left.\beta_{1}\right)$ were modeled as additive normal errors, i.e. $M^{\prime}=M+\varepsilon_{M}, \beta_{0}^{\prime}=\beta_{0}+\varepsilon_{\beta_{0}}$ and $\beta_{1}^{\prime}=\beta_{1}+\varepsilon_{\beta_{1}}$. The current fishing mortality $\left(F_{\text {cur }}\right)$ was generated from a gamma distribution $F_{\text {cur }} \sim \Gamma(\alpha, \beta) \alpha \beta$, where $\alpha \beta=\hat{F}_{c u r}, \alpha \beta^{2}=\hat{\sigma}_{F_{c u r}}^{2}$ to prevent unrealistic values (i.e., $\left.F_{\mathrm{cur}}<0\right)$.

To account for the likely correlation between life history parameters (Chen, 1996), the growth (in length) and natural mortality parameters were assumed to be correlated, as were the maturation 
parameters:

$$
\begin{gathered}
{\left[\begin{array}{c}
\varepsilon_{G R} \\
\varepsilon_{M}
\end{array}\right] \sim \mathbf{N}_{2}\left(\mathbf{0}, \boldsymbol{\Sigma}_{\mathbf{G R}, \mathbf{M}}\right) \text {, where } \boldsymbol{\Sigma}_{\mathbf{G R}, \mathbf{M}}=\left[\begin{array}{cc}
\sigma_{G R}^{2} & \rho_{G R, M} \sigma_{G R} \sigma_{M} \\
\rho_{G R, M} \sigma_{G R} \sigma_{M} & \sigma_{M}^{2}
\end{array}\right] \text { and }} \\
{\left[\begin{array}{c}
\varepsilon_{\beta_{0}} \\
\varepsilon_{\beta_{1}}
\end{array}\right] \sim \mathbf{N}_{2}\left(\mathbf{0}, \boldsymbol{\Sigma}_{\boldsymbol{\beta}_{0}, \boldsymbol{\beta}_{1}}\right) \text {, where } \boldsymbol{\Sigma}_{\boldsymbol{\beta}_{0}, \boldsymbol{\beta}_{1}}=\left[\begin{array}{cc}
\sigma_{\beta_{0}}^{2} & \rho_{\beta_{0}, \beta_{1}} \sigma_{\beta_{0}} \sigma_{\beta_{1}} \\
\rho_{\beta_{0}, \beta_{1}} \sigma_{\beta_{0}} \sigma_{\beta_{1}} & \sigma_{\beta_{1}}^{2}
\end{array}\right] ;}
\end{gathered}
$$

where $\rho_{G R, M}$ and $\rho_{\beta_{0}, \beta_{1}}$ were respectively the correlations between growth and natural mortality, and between the maturation parameters. $\rho_{\beta_{0}, \beta_{1}}$ was derived from our catch data (Lin, 2009). A reference value for $\rho_{G R, M}$, the correlation between natural mortality and growth in Japanese eels, was set to the estimate reported by Pauly (1980).

Growth parameters were derived from aging data based on otoliths (Lin and Tzeng, 2009a, b), fishing and natural mortality rates from a tag-recapture experiment (Lin et al., 2010a), maturation parameters from catch records for 1998-2008 (Lin, 2009), and other parameters from Cheng and Tzeng (1996) and Lin and Tzeng (2008) (Table 1). Details can be found in those earlier studies.

The generated parameters were used to calculate the biological reference points and key YPR and SPR values. Preliminary runs suggested that outputs based on 5000 replicates were identical up to the sixth decimal place; we therefore used 5000 replicates for all Monte Carlo analyses. Empirical distributions of $F_{\mathrm{BRP}}$ and key YPR and SPR values were estimated to determine the uncertainty associated with these quantities.

A stochastic decision-making framework (Helser et al., 2001; Chen and Wilson, 2002) was applied to assess this eel stock because there is uncertainty in estimates of both the current fishing mortality $\left(F_{\text {cur }}\right)$ and $F_{\mathrm{BRP}}\left(\right.$ e.g., $\left.F_{\max }\right)$. The $F_{\mathrm{BRP}}$ value at a given decision confidence, $x \%\left(F_{\mathrm{BRP},} x \%\right)$, was defined as the $F_{\mathrm{BRP}}$ value such that

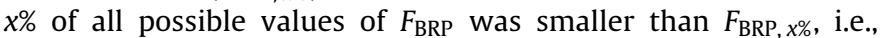
$P\left[F_{\mathrm{BRP}} \leq F_{\mathrm{BRP}, x \%}\right]=x \%$. The risk of biological overfishing, defined as the conditional probability of $F_{\text {cur }}$ being larger than $F_{\mathrm{BRP}}$ under a given decision confidence, $x \%\left(P\left[F_{\text {cur }}>F_{\mathrm{BRP}} \mid F_{\mathrm{BRP}}=F_{\mathrm{BRP}, x \%}\right]\right)$, was

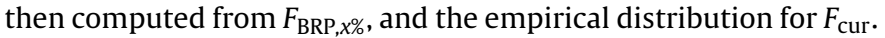
Therefore, the more confident (higher $x$ ) we are about $F_{\mathrm{BRP}}$, the higher the value of $F_{\mathrm{BRP}, \mathrm{x} \%}$, and the smaller the probability that

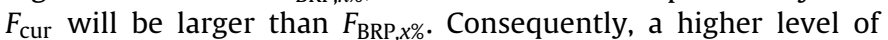
decision confidence results in a lower risk of biological overfishing.

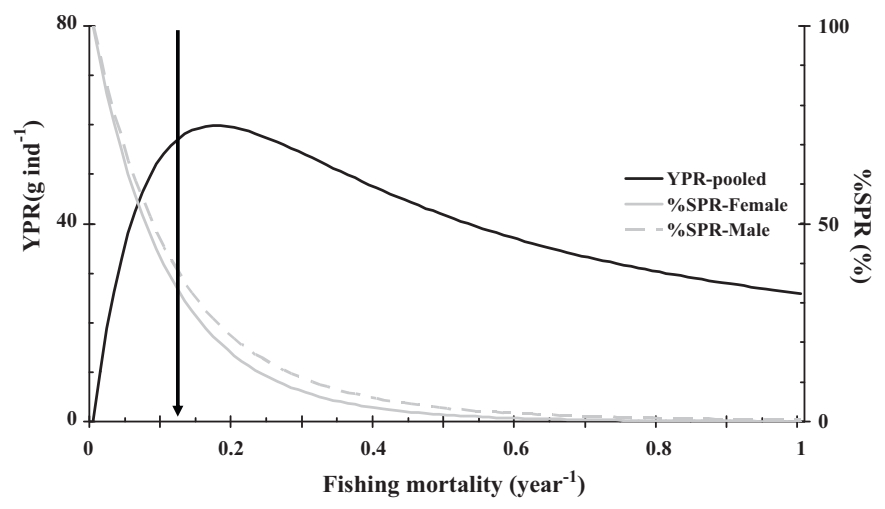

Fig. 1. Calculated yield-per-recruit (YPR, black curves and left $y$-axis) and relative spawning stock biomass-per-recruit (\%SPR, gray curves and right $y$-axis) of Japanese eel in the study region. Sexes were pooled in the YPR and separated in the \%SPR analyses. The vertical black line indicates the current fishing mortality $\left(0.12 \mathrm{yr}^{-1}\right)$.
Table 2

Estimated fishing mortality $(F)$-based biological reference points $\left(F_{\max }, F_{0.1}, F_{40 \%}\right.$, and $F_{50 \%} ; \mathrm{yr}^{-1}$ ) for the Japanese eel fishery in the lower reaches of the Kao-Ping River in southern Taiwan based on the yield-per-recruit (YPR) and spawning stock biomassper-recruit (SPR) models. $F_{\text {cur }}$ is the current fishing mortality rate $\left(\mathrm{yr}^{-1}\right) . Y P R_{\max }$ is the maximal YPR value $\left(\mathrm{g}_{\text {ind }}{ }^{-1}\right) ; S P R_{F c u r}$ is the SPR values at $F=F_{\text {cur }}\left(\mathrm{g} \mathrm{ind}^{-1}\right)$; $S P R_{0}$ is the SPR values at $F=0\left(\mathrm{~g}\right.$ ind $\left.^{-1}\right)$; and the relative SPR (\%SPR) is equal to $S P R_{\text {Fcur }} \times S P R_{0}{ }^{-1} \times 100 \%$. Sexes were pooled for $F_{\text {cur }}, F_{\max }, F_{0.1}$, and $Y P R_{\max }$.

\begin{tabular}{llll}
\hline & Female & & Male \\
\hline$F_{\text {cur }}$ & & 0.120 & \\
$F_{\max }$ & & 0.165 & \\
$F_{0.1}$ & 0.115 & \\
$F_{40 \%}$ & & & 0.113 \\
$F_{50 \%}$ & 0.094 & & 0.084 \\
$Y P R_{\max }$ & 0.070 & 61.4 & \\
$S P R_{\text {Fcur }}$ & & & 214.9 \\
$S P R_{0}$ & 329.2 & & 565.4 \\
$\% S P R$ & 1048.8 & & 38.0
\end{tabular}

\section{Results}

\subsection{Deterministic YPR and SPR analyses}

$F_{\max }$ was $0.165 \mathrm{yr}^{-1}$ corresponding to a maximum YPR value $\left(Y P R_{\max }\right)$ of $61.4 \mathrm{~g}_{\text {individual }}{ }^{-1}\left[(\mathrm{ind})^{-1}\right]$, and $F_{0.1}$ was $0.115 \mathrm{yr}^{-1}$ (Table 2). The current fishing mortality rate on yellow and silver eels $\left(F_{\text {cur }}=0.120 \mathrm{yr}^{-1}\right)$ slightly exceeded $F_{0.1}$, but was smaller than $F_{\text {max }}$.

$F_{40 \%}$ was 0.094 and $0.113 \mathrm{yr}^{-1}$ for females and males respectively, while the corresponding values for $F_{50 \%}$ were 0.070 and $0.084 \mathrm{yr}^{-1}$ (Table 2), all of which are smaller than $F_{\text {cur. SPR }}$ was higher for females $\left(S P R_{0}=1048.8 \mathrm{~g}\right.$ ind $\left.^{-1}\right)$ than for males ( $565.4 \mathrm{~g}$ ind $^{-1}$ ) in the absence of exploitation, but the SPR of females was slightly lower than that of males when fishing mortality increased (Fig. 1). Under $F_{\text {cur }}$, the SPR declined to $31 \%$ and $38 \%$ of $S P R_{0}$ in females and males, respectively.

\subsection{Evaluation of minimum legal lengths}

YPR increased with $F$ and $L_{\text {min }}$. At $F_{\text {cur }}$, the YPR was maximized (at around $70 \mathrm{~g}$ ind $^{-1}$ ) at an $L_{\mathrm{min}}$ of around $500 \mathrm{~mm}$. YPR values reached a plateau of $100 \mathrm{~g}^{-1} \mathrm{in}^{-1}$ when $L_{\min }$ was $600-700 \mathrm{~mm}$ and $F$ was $>0.4 \mathrm{yr}^{-1}$ (Fig. 2). \%SPR increased with increasing $L_{\min }$ for both sexes (Fig. 3). At $F_{\text {cur }}$, the $L_{\min }$ that produced the highest YPR values $(500 \mathrm{~mm})$ resulted in \%SPR being slightly higher than $50 \%$ for both sexes. However, optimizing YPR $\left(L_{\min } 600-700 \mathrm{~mm}, F>0.4 \mathrm{yr}^{-1}\right)$

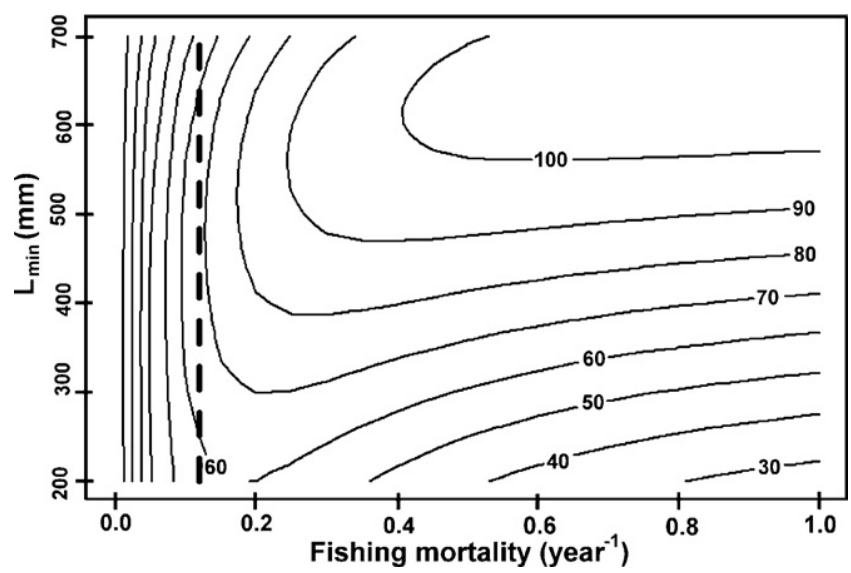

Fig. 2. Isopleths of sex-pooled yield-per-recruit under different combinations of fishing mortality rates and minimum legal sizes $\left(L_{\min }\right)$. No minimal legal size is set, but current fishing practice conforms to a minimum size of $200 \mathrm{~mm}$. The black broken line indicates current fishing mortality. 


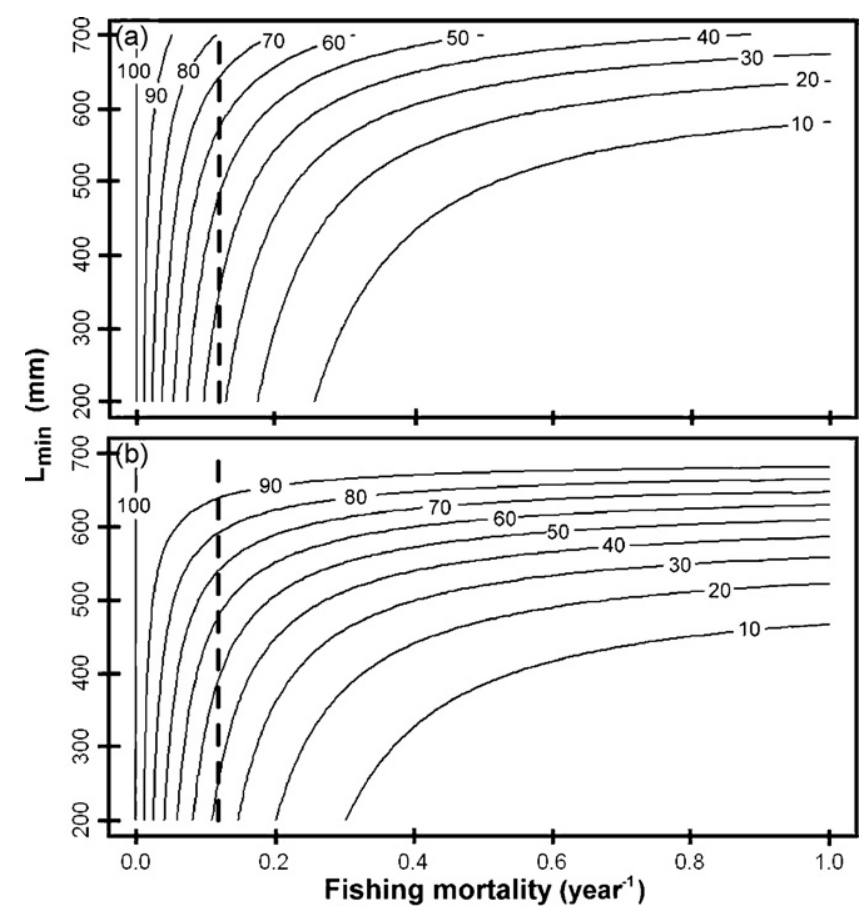

Fig. 3. Isopleths of the relative spawning stock biomass-per-recruit under different combinations of fishing mortality rate and minimum legal size $\left(L_{\min }\right)$ for $(\mathrm{a})$ females and (b) males. The black broken line indicates current fishing mortality.

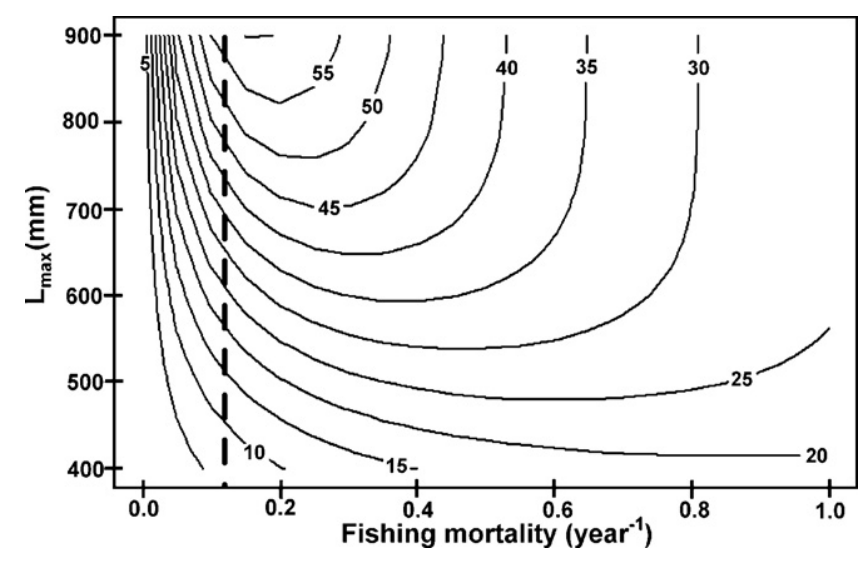

Fig. 4. Isopleths of sex-pooled yield-per-recruit data under different combinations of fishing mortality rate and maximum legal size $\left(L_{\max }\right)$. The black broken line indicates current fishing mortality.

might result in \%SPR being $<50 \%$ in females (Fig. 3a) and $<60 \%$ in males (Fig. 3b).

\subsection{Evaluation of maximum legal lengths}

Compared to $L_{\min }$, implementation of a maximum legal length $\left(L_{\max }\right)$ resulted in a decrease in YPR (Fig. 4). YPR decreased from approximately 55 to $5 \mathrm{~g}$ ind $^{-1}$ when $L_{\max }$ was changed from unregulated ( $>800 \mathrm{~mm}$ ) to $400 \mathrm{~mm}$. YPR increased more slowly with an increasing $F$ at a smaller $L_{\max }$. On the other hand, \%SPR drastically increased with a decreasing $L_{\max }$ (Fig. 5 ) for both sexes. At $F_{\text {cur }}$ \%SPR increased from approximately $33 \%$ (without regulation of $L_{\max }$ ) to $>70 \%$ when $L_{\max }$ values were $>800$ and $650 \mathrm{~mm}$ for females and males, respectively. The increase in \%SPR slowed when $L_{\max }$ was further reduced. \%SPR appeared unaffected by $L_{\max }$ and only decreased with $F$ when $L_{\max }$ was $<600 \mathrm{~mm}$ for females and $<500 \mathrm{~mm}$ for males (Fig. 5).

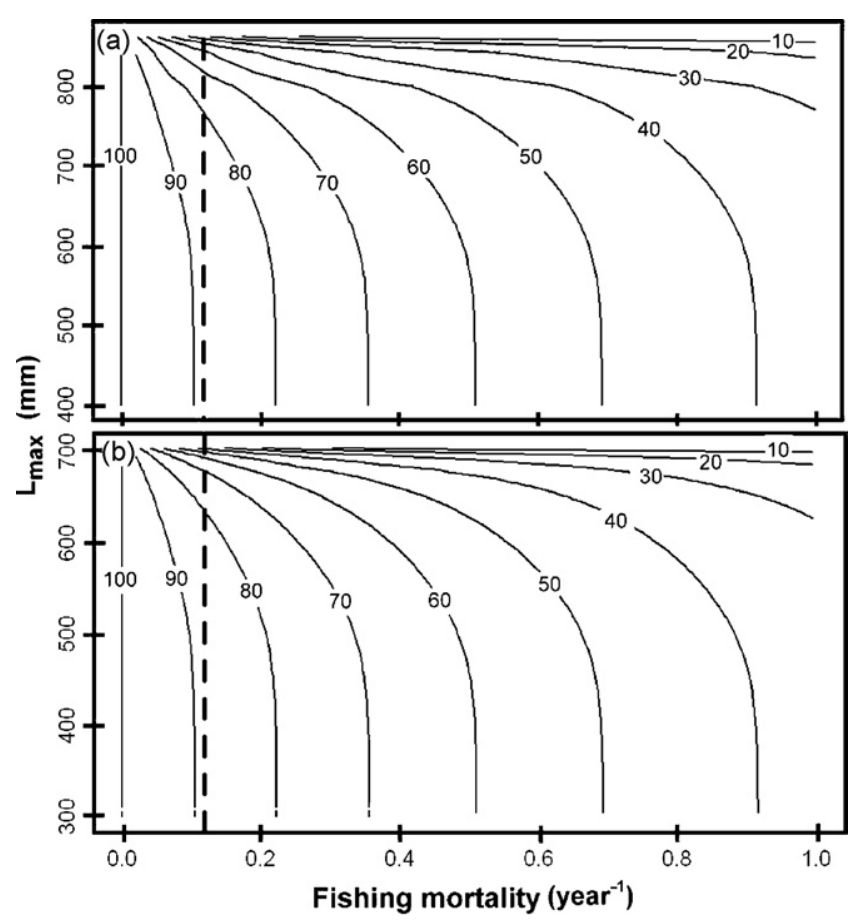

Fig. 5. Isopleths of relative spawning stock biomass-per-recruit data under different combinations of fishing mortality rate and maximum legal size $\left(L_{\max }\right)$ for (a) females and (b) males. The black broken line indicates current fishing mortality.

\subsection{Incorporation of parameter uncertainty into the per-recruit analysis}

Average values of $F_{\max }, F_{0.1}, F_{40 \%}$, and $F_{50 \%}$ after accounting for the uncertainty of input parameters in the per-recruit analysis were identical to estimates from the deterministic model to the third decimal place. \%SPR was about 2-3\% higher than that from the deterministic model when parameter uncertainty was accounted for. However, $Y P R_{\max }, S P R_{\mathrm{Fcur}}$, and $S P R_{0}$ were about $12-35 \%$ larger than those from the deterministic model (Table 3 ).

$F_{\max }$ and $F_{0.1}$ had relatively small coefficients of variation (CVs, of $1-1.3 \%)$, and their distributions were nearly symmetrical. In contrast, the amount of uncertainty for $F_{40 \%}$ and $F_{50 \%}$ was relatively high, with CVs of 7.5-8.9\%, and distributions being symmetrical or slightly skewed to the right for females. Their distributions were also flatter (platykurtic) compared to $F_{\max }$ and $F_{0.1}$ (Fig. $6 \mathrm{a}$ and b).

$Y P R_{\max }, S P R_{F c u r}$, and $S P R_{0}$ had higher $C V$ values, ranging $53-111 \%$, implying that they were more sensitive to the input parameter uncertainty than was $F_{\mathrm{BRP}}$. Moreover, the distributions of $Y P R_{\max }, S P R_{\mathrm{Fcur}}$, and $S P R_{0}$ were highly skewed with a long tail extending to the right, i.e., YPR and SPR values 2-3-times higher than the average value occasionally occurred (Fig. 7a-c). \%SPR varied moderately, with CVs of $25-32 \%$, and its distribution was symmetrical around the mean (Fig. 7d).

Probabilities of $F_{\text {cur }}$ being larger than $F_{\max }$ were $15-20 \%$, as the confidence level changed from values of $>99.95 \%$ to $<0.05 \%$ (Fig. 8). The probability of $F_{\text {cur }}$ being larger than $F_{0.1}$ was very high (58-66\%). Probabilities were relatively high for $F_{40 \%}$ (50.6-93.3\% for females and $26.3-82.3 \%$ for males) and $F_{50 \%}(84.7-99.1 \%$ for females and 73.2-96.7\% for males) (Fig. 8).

\section{Discussion}

Knowledge of the status and exploitation level of $A$. japonica is limited compared to that for other well-studied eel species (e.g., $A$. anguilla, A. rostrata, $A$. australis, and $A$. dieffenbachii). Collaboration 

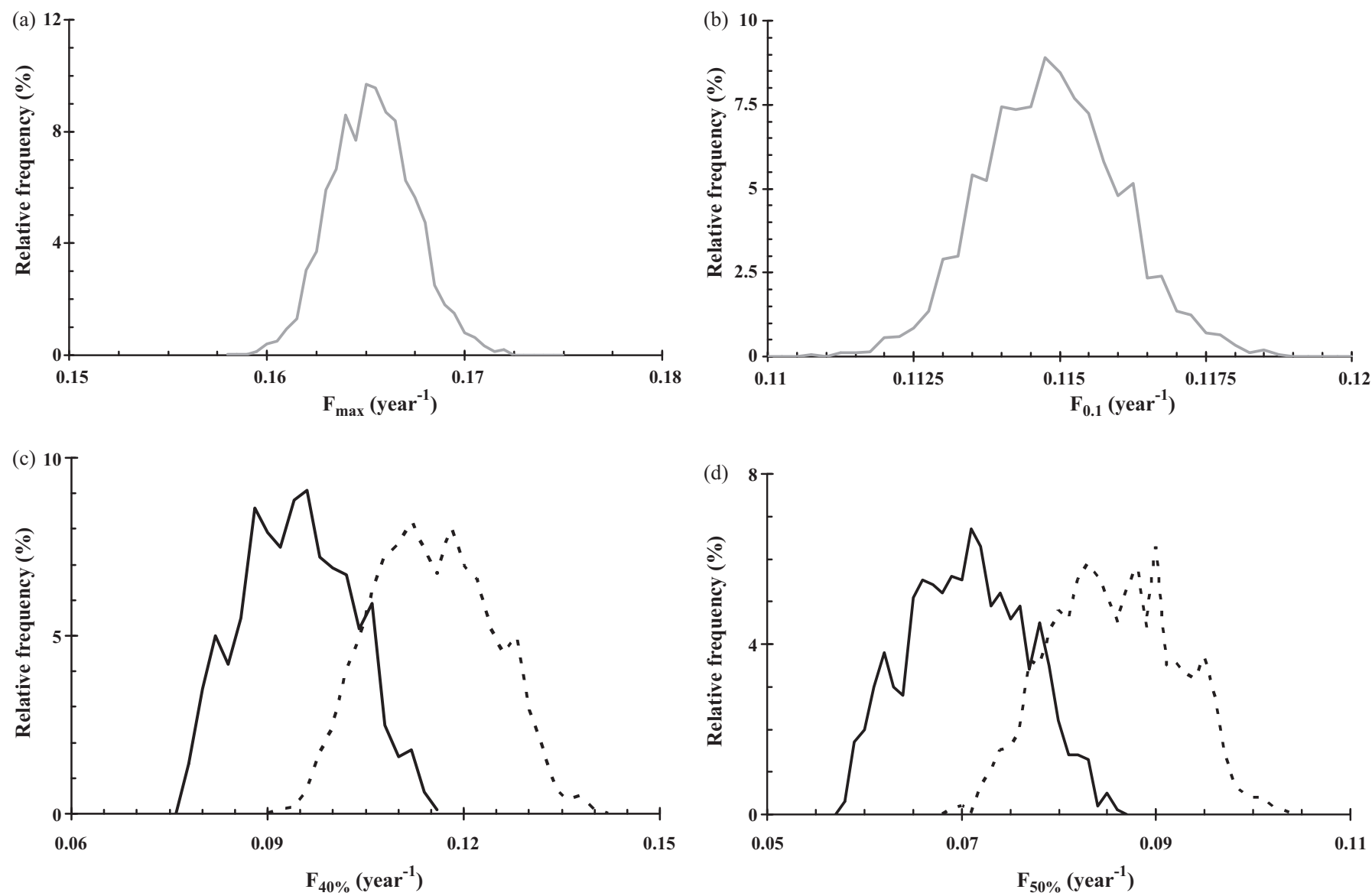

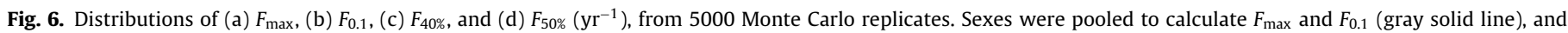
separated when calculating $F_{40 \%}$ and $F_{50 \%}$. The black solid and dotted lines in this figure and Fig. 7 indicate females and males, respectively.

among different countries and integration of data from different regions are required to assess a widely distributed species (as in the case for A. anguilla; Dekker, 2003a). However, eel exploitation is usually evaluated at smaller scales due to a lack of integrated data at broad geographic scales. The International Council for the Exploitation of the Sea (ICES) suggests applying practical management actions within catchments (a "management stock", ICES, 2003). Although undertaken on a smaller scale, local-scale studies are the foundation of larger-scale studies (e.g., Dekker, 1999, 2003b), and these have been widely conducted for other anguillid species (e.g., De Leo and Gatto, 1995; Bevacqua et al., 2007 for $A$. anguilla; Hoyle and Jellyman, 2002; Chisnall et al., 2003 for A. australis and A. dieffenbachii; and Robitaille et al., 2003; Weeder and Uphoff, 2009 for A. rostrata).
This study showed that this local stock is nearly fully exploited, and the contribution of the SPR from this local stock to the total Japanese eel stock is below minimal thresholds under current exploitation pressures. Moreover, YPR-related $F_{\mathrm{BRP}}\left(F_{\max }\right.$ and $\left.F_{0.1}\right)$ values were higher than SPR-related $F_{\mathrm{BRP}}\left(F_{40 \%}\right.$ and $\left.F_{50 \%}\right)$ values for both sexes, which means that optimizing the local YPR may not result in a sustainable fishery with a sufficient SPR. As a consequence, a conflict may exist between global restrictions on maintaining the SPR and local management objectives (Dekker, 2008).

The exploitation of yellow and silver eels should be regulated to achieve a sufficient level of spawning biomass-per-recruit. Restricting $F$ is perhaps the most direct way that a $42 \%$ reduction in $F_{\text {cur }}$ can produce an $F$ of $<F_{50 \%}$. However, it would also reduce the YPR by

Table 3

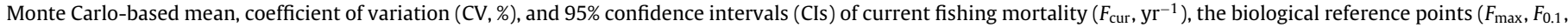

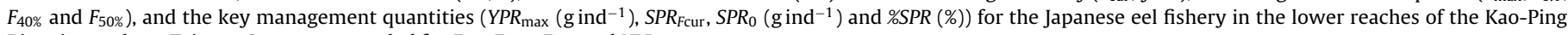
River in southern Taiwan. Sexes were pooled for $F_{\mathrm{cur}}, F_{\max }, F_{0.1}$, and $Y P R_{\max }$.

\begin{tabular}{|c|c|c|c|c|c|c|}
\hline & \multicolumn{3}{|l|}{ Female } & \multicolumn{3}{|l|}{ Male } \\
\hline & Mean & $\mathrm{CV}$ & $95 \% \mathrm{CI}$ & Mean & $\mathrm{CV}$ & $95 \% \mathrm{CI}$ \\
\hline$F_{\text {cur }}$ & 0.120 & 27.1 & $0.067-0.196$ & & & \\
\hline$F_{\max }$ & 0.165 & 1.3 & $0.161-0.169$ & & & \\
\hline$F_{0.1}$ & 0.115 & 1.0 & $0.112-0.117$ & & & \\
\hline$F_{40 \%}$ & 0.094 & 8.9 & $0.079-0.110$ & 0.114 & 7.9 & $0.098-0.131$ \\
\hline$F_{50 \%}$ & 0.070 & 8.5 & $0.059-0.082$ & 0.085 & 7.5 & $0.073-0.097$ \\
\hline$Y P R_{\max }$ & 70.8 & 53.1 & $22.6-161.8$ & & & \\
\hline$S P R_{F c u r}$ & 408.2 & 111.2 & $12.8-1632.2$ & 291.1 & 85.9 & $49.2-2194.0$ \\
\hline$S P R_{0}$ & 1178.4 & 93.1 & $63.4-3815.1$ & 699.8 & 96.7 & $13.4-1041.9$ \\
\hline$\% S P R$ & 32.0 & 31.5 & $14.0-52.4$ & 39.3 & 25.3 & 21.1-59.1 \\
\hline
\end{tabular}



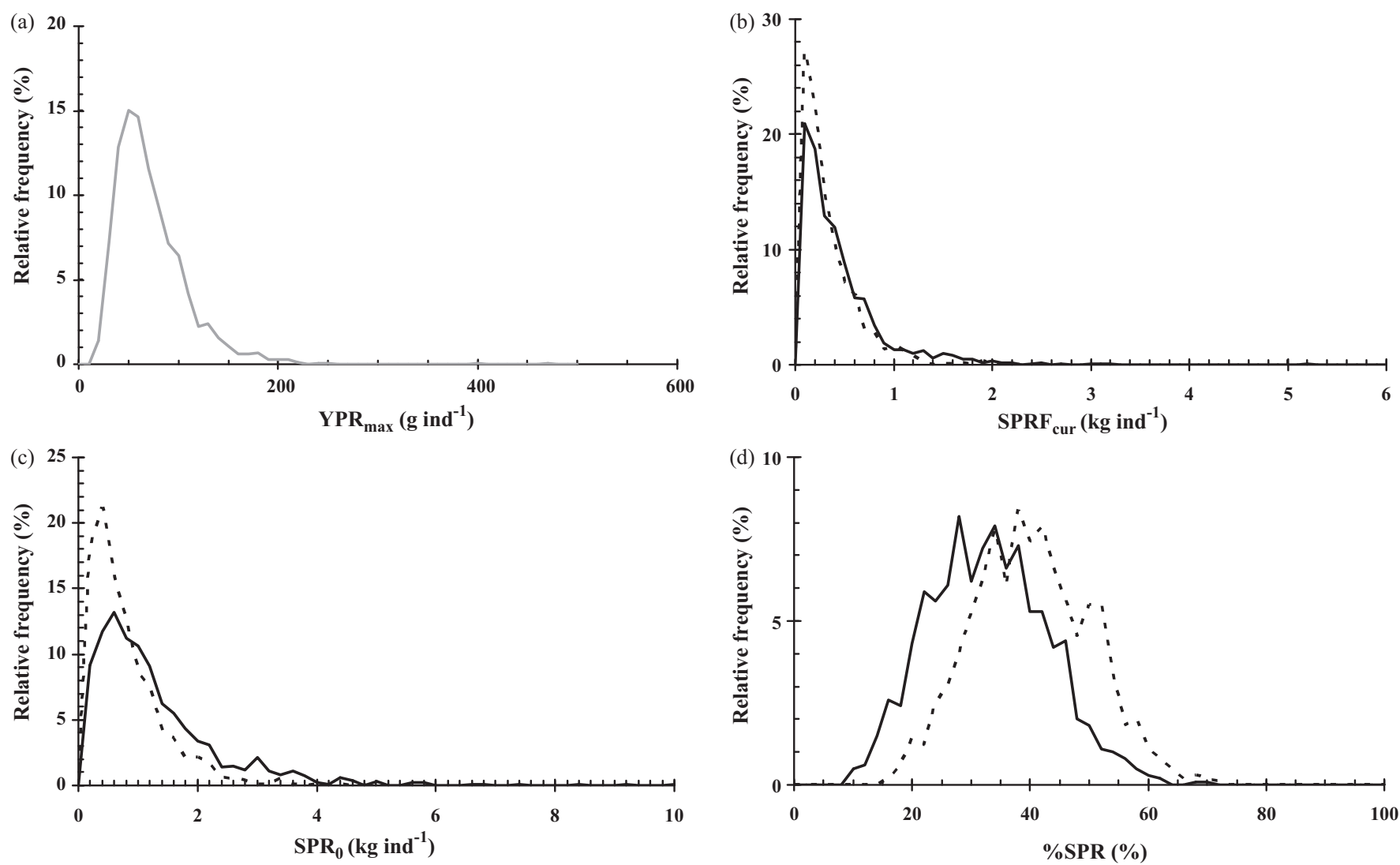

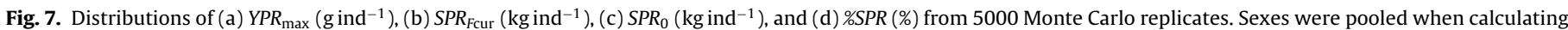
$Y P R_{\max }$ (gray solid line), and separated when calculating $S P R_{F c u r}, S P R_{0}$ and $\% S P R(\%)$.

approximately $83 \%$. Implementing minimum $\left(L_{\mathrm{min}}\right)$ and maximum ( $L_{\max }$ ) legal lengths is likely to be effective alternatives, because $L_{\min }$ is able to enhance both the YPR and \%SPR (e.g., Goodyear, 1993; King, 2007 ), and $L_{\max }$ has the potential to effectively protect \%SPR (Hoyle and Jellyman, 2002). The YPR was close to the maximum at an $L_{\mathrm{min}}$ of $500 \mathrm{~mm}$ under $F_{\text {cur }}$, and \%SPR increased to $>50 \%$ for females and $>60 \%$ for males (Figs. 2 and 3). However, selectively harvesting large individuals with an $L_{\min }$ may result in an age-truncated and juvenescent stock with unstable dynamics (Anderson et al., 2008). Setting a maximum legal length $\left(L_{\max }\right)$ might be a better practice to stabilize the stock than setting an $L_{\min }$ because of the reduced fishing pressure on large individuals. However, YPR declined considerably with a low $L_{\max }$. If maximum legal lengths of $850 \mathrm{~mm}$ for females and around $680 \mathrm{~mm}$ for males were implemented, a sufficient level of $\% \operatorname{SPR}(>50 \%)$ would be expected, with a slight reduction of $12.5 \%$ in the YPR under $F_{\text {cur }}$ (Figs. 4 and 5 ).

Since eels of different sexes cannot be harvested separately and stocks of male silver eels can be enhanced by stocking cultured eels in rivers (Lin et al., 2010b), we suggest setting a management goal with regard to female spawning biomass for maintaining future recruitment. In addition to restrictions on $F$ and minimum and maximum legal sizes, other management strategies such as limiting or banning eel fishing in winter, when small fish are recruited to the fishing ground, were also suggested by Lin and Tzeng (2008).

The uncertainty of input parameters introduces additional variations into the estimation of $F_{\mathrm{BRP}}$ (Chen and Wilson, 2002). The considerable uncertainty of $F_{\mathrm{BRP}}$ from the SPR analysis was possibly due to variations in the parameters of the maturation curves. Furthermore, $F_{40 \%}$ had a slightly higher CV than $F_{50 \%}$ in this study, which is in accordance with Chang et al. (2009) where $F_{10 \%}$ had the highest $\mathrm{CV}$, followed by $F_{20 \%}, F_{30 \%}$, and $F_{40 \%}$ for the fishery of the pronghorn spiny lobster (Panulirus penicillatus). Therefore, variation in $F_{S \%}$ (i.e., the fishing mortality rate corresponding to $S \%$ of the spawning stock biomass-per-recruit at the unfished level), possibly increases with a decrease in $S$, at least for values of $S$ of 10-50.

This study suggested that the uncertainty in parameter estimation might not bias estimates of $F_{\mathrm{BRP}}$, because mean values of $F_{\mathrm{BRP}}$ were nearly the same without this uncertainty (Tables 2 and 3 ). The symmetrical distributions in Fig. 6 further indicated that this uncertainty introduced only random deviations around the mean and had little influence on their mean values. Conversely, the precision and accuracy of $Y P R_{\max }, S P R_{0}$, and $S P R_{F c u r}$ appeared to be greatly influenced by this uncertainty, as indicated by different mean values with and without including parameter uncertainty, and highly skewed distributions. These key YPR and SPR values can be used to calculate expected yields (i.e., acceptable biological catch) and spawning biomass, with and without exploitation, by multiplying by the mean recruitment and then entering these values into other assessment models (Sissenwine and Shepherd, 1987; Clark, 2002). Therefore, these assessment models would be also be sensitive to the uncertainty in the parameter estimates.

Because the appropriate level of \%SPR is still unclear and has not been examined for the Japanese eel, $F_{40 \%}$ and $F_{50 \%}$ were arbitrarily applied based on theoretical considerations given the variability of recruitment and a lack of knowledge of the stock-recruitment relationships (Clark, 1993, 2002; Gabriel and Mace, 1999), and values from other eel species. A 40\% escapement of adult silver eels of A. anguilla from each river basin with respect to the undisturbed level was decided by the European Commission (CEC, 2006). A $\%$ SPR of $50 \%$ was suggested by Hoyle and Jellyman (2002) given the catadromous life histories of $A$. dieffenbachii and $A$. australis. An even more-conservative level of $>60 \%$ of silver eel escapement was 

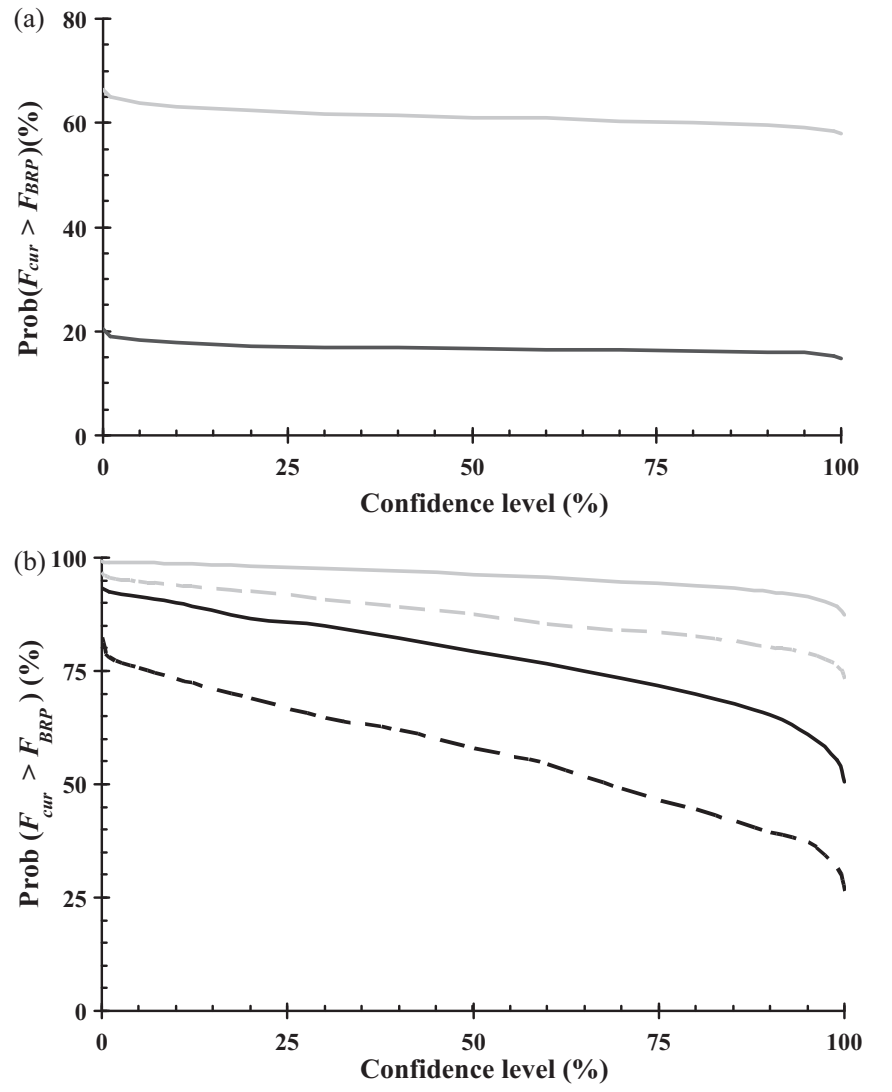

Fig. 8. (a) Probabilities of the current fishing mortality $\left(F_{\text {cur }}\right)$ being higher than $F_{\max }$ (black) and $F_{0.1}$ (gray), and (b) probabilities of $F_{\text {cur }}$ being higher than $F_{40 \%}$ (black) and $F_{50 \%}$ (gray) for females (solid line) and males (broken line) at the given confidence levels. Confidence levels ranged from $<0.05 \%$ to $>99.95 \%$.

required to permit the possible long-term (60-140-year) recovery of $A$. anguilla (ICES, 2006). It is possible that a limit of $40 \%$ SPR would still be insufficient for the declining Japanese eel stock (Dekker, 2003c). Therefore, studies examining the minimum level of \%SPR and other management applications are necessary.

There are several caveats related to this study. First, only the uncertainty in the estimation of parameters was quantified and incorporated into the per-recruit analysis. However, other sources of errors (e.g., stochastic variation in parameters, Quinn and Deriso, 1999) may also have biased estimates of $F_{\mathrm{BRP}}$. Thus, the uncertainty of the $F_{\mathrm{BRP}}$ and key YPR and SPR values for the Japanese eel are probably greater than estimated. Second, this study was restricted to the post-elver stage. Exploitation of yellow and silver eels was evaluated under the assumption that the recruitment (elvers) had already been fished by the elver fishery. This short fishing period (4-10 days) may result in losses of $44-75 \%$ of the initial immigrating population (Tzeng, 1984). The additional fishing mortality of elvers leads to underestimated mortality during the early part of life, and then underestimates $S P R_{0}$ and overestimates \%SBR. Third, applying conservative levels of \%SPR may conflict with local exploitation objectives (i.e., optimizing the YPR).

Restrictions on fisheries alone may be insufficient to ensure sustainable exploitation. Measures aimed at other impacts on habitat quality, quantity, and accessibility of Japanese eels will also be required (ICES, 2006). Although the Kao-Ping River is the largest river supporting the commercial yellow and silver eel fisheries, it is subject to both anthropogenic (e.g., sewage discharge and dams) and natural disturbances (e.g., typhoon Morakot in August 2009). Investigations of these effects on eels and habitat are also needed.

\section{Acknowledgements}

This study was financially supported by the National Science Council of the R.O.C. (NSC94-2313-B-002-070). The authors thank Dr. Yu-San Han for updating the eel database, Prof. Wann-Nian Tzeng's students and assistants for data collection, Dr. Su-Lean Chang for the collection of eel specimens, and Mr. Brian Jessop, Dr. Daniele Bevacqua, Dr. André Punt, Su-zan Yeh, and Dr. Chris Harrod for helpful comments on earlier drafts of the manuscript.

\section{Appendix A.}

Definition of symbols used in yield- and spawner-biomass per recruit:

$a, b: \quad$ parameters in a allometric weight-length relationship:

$W=a L^{b}$

F: $\quad$ instantaneous fishing mortality rate $\left(\mathrm{yr}^{-1}\right)$.

K: $\quad$ Brody growth coefficient in von Bertalanffy growth

$N(t): \quad$ function $\left(\mathrm{yr}^{-1}\right)$.

$N(t): \quad$ the population size at time $t$ (number of fish).

$L_{c}: \quad$ length at first capture $(\mathrm{mm})$.

$L_{\infty}: \quad$ asymptotic length in von Bertalanffy growth function

(mm).

M: $\quad$ instantaneous natural mortality rate $\left(\mathrm{yr}^{-1}\right)$

$S(t): \quad$ the proportion of silver eels at time $t(\%)$. It is assumed to change with total length of the eels and follow a logistic

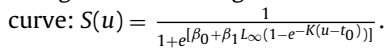

$t_{0}$ : the hypothetical age when body size is zero ( $\quad$ yr).

$t_{c}$ : the catch; the age at first capture.

$t_{r}: \quad$ the age at recruitment (yr).

$t_{\max }: \quad$ the maximum age.

$W(t): \quad \quad$ eel weight at time $t(\mathrm{~g})$.

$\beta_{0}, \beta_{1}$ : maturation parameters in the logistic maturation curve.

\section{References}

Anderson, C.N.K., Hsieh, C.H., Sandin, S.A., Hewitt, R., Hollowed, A., Beddington, J., May, R.M., Sugihara, G., 2008. Why fishing magnifies fluctuations in fish abundance. Nature 452, 835-839.

Bevacqua, D., Melià, P., Crivelli, J., Gatto, M., De Leo, G.A., 2007. Multi-objective assessment of conservation measures for the European eel (Anguilla anguilla): an application to the Camargue lagoons. ICES J. Mar. Sci. 64, 1483-1490.

CEC, 2006. Report on the proposal for a council regulation establishing measures for the recovery of the stock of European eel. Commission for the European Communities A6-0140/2006.

Chang, C.W., Tzeng, W.N., 1990. Traditional fishing methods for eels in the river. Fish. Exten. NTU 12, 27-36 (in Chinese).

Chang, Y.J., Sun, S.L., Chen, Y., Yeh, S.Z., Chiang, W.C., 2009. Incorporating uncertainty into the estimation of biological reference points for a spiny lobster (Panulirus penicillatus) fishery. NZ. J. Mar. Freshw. Res. 43, 429-442.

Chen, Y., 1996. A Monte Carlo study on impacts of the size of subsample catch on estimation of fish stock parameters. Fish. Res. 26, 207-223.

Chen, Y., Wilson, C., 2002. A simulation study to evaluate impacts of uncertainty on the assessment of American lobster fishery in the Gulf of Maine. Can. J. Fish. Aquat. Sci. 59, 1394-1403.

Cheng, P.W., Tzeng, W.N., 1996. Timing of metamorphosis and estuarine arrival across the dispersal range of the Japanese eel Anguilla japonica. Mar. Ecol. Prog. Ser. 113, 89-96.

Chisnall, B.L., Martin, M.L., Hicks, B.J., 2003. Effect of harvest on size, abundance and production of freshwater eels Anguilla australis and A. dieffenbachii in a New Zealand Stream. In: Dixon, A.D. (Ed.), Biology, Management, and Protection of Catadromous eels. Am. Fish. Soc. Sym. 33, 177-189.

Clark, W.G., 1993. The effect of recruitment variability on the choice of a target level of spawning biomass per recruit. In: Kruse, G., Marasco, R.J., Pautzke, C., Quinn II, T.J. (Eds.), Proceedings of the International Symposium on Management Strategies for Exploited Fish Populations. Alaska Sea Grant College Program Report No. 93-02. University of Alaska Fairbanks, pp 233-246.

Clark, W.G., 2002. F35\% revisited ten years later. North Am. J. Fish. Manage. 22, 251-257.

Dekker, W., 1999. A Procrustean assessment of the European eel stock. ICES J. Mar. Sci. 57, 938-947.

Dekker, W., 2000. Impact of yellow eel exploitation on spawner production in Lake IJsselmeer, The Netherland. Dana 12, 25-40.

Dekker, W., 2003a. On the distribution of the European eel and its fisheries. Can. J. Fish. Aquat. Sci. 60, 787-799.

Dekker, W., 2003b. Did lack of spawners cause the collapse of the European eel, Anguilla anguilla? Fish. Manage. Ecol. 10, 365-376.

Dekker, W., 2003c. Epilogue: worldwide decline of eel resources necessitates immediate action. Fisheries 28, 28-30. 
Dekker, W. 2008. Coming to grips with the eel stock slip-sliding away. In: Schechter, M.G, Leonard, N.J. (Eds.), International Governance of Fisheries Ecosystems: Learning from the Past, Finding Solutions for the Future. Am. Fish. Soc. Sym. 62.

De Leo.F G.A., Gatto, M., 1995. A size- and age-structured model of the European eel (Anguilla anguilla L.). Can. J. Fish. Aquat. Sci. 52, 1351-1367.

Deriso, R.B., 1987. Optimal $F_{0.1}$ criteria and their relationship to maximum sustainable-yield. Can. J. Fish. Aquat. Sci. 44, 339-348.

Gabriel, W.L., Mace, P.M., 1999. A review of biological reference points in the context of the precautionary approach. Proceedings, 5th NMFS NSAW. NOAA Tech. Memo. NMFS-F/SPO-40.

Goodyear, C.P., 1993. Spawning stock biomass per recruit in fisheries management: foundation and current use. In: Smith, S.J., Hunt, J.J., Rivard, D. (Eds.), Risk Evaluation and Biological Reference Points for Fisheries Management. Can. Spec. Publ. Fish. Aquat. Sci. 120, 67-81.

Grabowski, R., Chen, Y., 2004. Incorporating uncertainty into the estimation of the biological reference points $F_{0.1}$ and $F_{\max }$ for the Maine green sea urchin (Strongylocentrotus droebachiensis) fishery. Fish. Res. 68, 367-371.

Han, Y.S., Tzeng, W.N., 2006. Use of the sex ratio as a means of resources assessment for the Japanese eel Anguilla japonica: a case study in the Kaoping River of Taiwan. Zool. Stud. 45, 255-263.

Han, Y.S., Liao, I.C., Huang, Y.S., He, J.T., Chang, C.W., Tzeng, W.N., 2003. Synchronous changes of morphology and gonadal development of silvering Japanese eel Anguilla japonica. Aquaculture 219, 783-796.

Han, Y.S., Hung, C.L., Liao, Y.F., Tzeng, W.N., 2010. Population genetic structure of the Japanese eel Anguilla japonica: panmixia at spatial and temporal scales. Mar. Ecol. Prog. Ser. 401, 221-232.

Helser, T.E., Sharov, T., Kahn, D.M., 2001. A stochastic decision-based approach to assessing the Delaware Bay blue crab (Callinectes apidus) stock. In: Berkson, J.M., Kline, L.L., Orth, D.J. (Eds.), Incorporating Uncertainty into Fishery Models. American Fisheries Society Publication, Bethesda, MD, pp. 63-82.

Hoyle, S.D., Jellyman, D.J., 2002. Longfin eels need reserves: modeling the effects of commercial harvest on the stocks of New Zealand eels. Mar. Freshw. Res. 53, $887-895$.

ICES, 2002. Report of the ICES/EIFAC Working Group on Eels. ICES Document CM 2002/ACFM:03.

ICES, 2003. Report of the ICES/EIFAC Working Group on Eels. ICES Document CM 2003/ACFM: 06.

ICES, 2006. Report of the ICES/EIFAC Working Group on Eels (WGEEL), 23-27 January 2006, Rome, Italy. ICES Document CM 2006/ACFM: 16.

King, M., 2007. Fisheries Biology, Assessment and Management, 2nd ed. Blackwell Publishing, Oxford, UK, 382 pp.

Kruse, G.H., Jeffrey Barnhart, P., Rosenkranz, G.E., 2005. Management of the data-limited weathervane scallop fishery in Alaska fisheries assessment and management in data-limited situations. Alaska Sea Grant College Program. AK-SG-05-02, 2005.

Lin, Y.J., 2009. Population dynamics and sustainable use of Japanese eel (Anguilla japonica) in Kao-Ping River: application of YPR and SPR models. Doctor Thesis. Institute of Fisheries Science, National Taiwan University.

Lin, Y.J., Tzeng, W.N., 2008. Effects of shrimp net and cultured eels on the wild population of Japanese eel Anguilla japonica in Kao-Ping River Taiwan. J. Fish. Soc. Taiwan 35, 61-73.

Lin, Y.J., Tzeng, W.N., 2009a. Validation of annulus in otolith and estimation of growth rate for Japanese eel Anguilla japonica in tropical southern Taiwan. Environ. Biol. Fish. 84, 79-87.
Lin, Y.J., Tzeng, W.N., 2009b. Modelling the growth of Japanese eel Anguilla japonica in the lower reach of the Kao-Ping River, southern Taiwan: an information theory approach. J. Fish Biol. 75, 100-112.

Lin, Y.J., Chang, S.L., Chang, M.Y., Lin, S.H., Chen, T.I., Su, M.S., Su, W.C., Tzeng, W.N., 2010a. Comparison of the recapture rate and estimates of fishing and natura mortality rate of Japanese eel (Anguilla japonica) between origins and marks in a mark-recapture experiment in Kao-Ping River, southern Taiwan. Zool. Stud. 49 (5), 616-624.

Lin, Y.J., Iizuka, Y., Tzeng1, W.N., 2010b. Potential contributions by escaped cultured eels to the wild population of Japanese eel Anguilla japonica in the Kao-Ping River. J. Fish. Soc. Taiwan 36 (3), 179-189.

Owen, W.J., 2006. The R guide Version 2.2. Department of Mathematics and Computer Science, University of Richmond.

Pauly, D., 1980. On the interrelationships between natural mortality, growth parameters and mean environmental temperatures in 175 fish stocks. ICES J. Mar. Sci. 39, 175-192.

Quinn, J.T.II., Deriso, R.B., 1999. Quantitative Fish Dynamics. Oxford University Press, New York, 542 pp.

Robitaille, J.A., Bérubé, P., Tremblay, S., Verreault, G., 2003. Eel fishing in the Great Lakes/St. Lawrence River system during the 20th century: signs of overfishing. In: Dixon, A.D. (Ed.), Biology, Management, and Protection of Catadromous eels. Am. Fish. Soc. Sym. 33, 253-262.

Sang, T.K., Chang, H.Y., Chen, C.T., Hui, C.F., 1994. Population structure of the Japanese eel Anguilla japonica. Mol. Biol. Evol. 11, 250-260.

Sissenwine, M.P., Shepherd, J.G., 1987. An alternative perspective on recruitment overfishing and biological reference points. Can. J. Fish. Aquat. Sci. 44, 913-918.

Teng, H.Y., Lin, Y.S., Tzeng, C.S., 2009. A new Anguilla species and a reanalysis of the phylogeny of freshwater eels. Zool. Stud. 48 (6), 808-822.

Tesch, F.W., 2003. The Eel, $3^{\text {rd }}$ ed. Blackwell Science, Oxford, UK.

Tseng, M.C., Tzeng, W.N., Lee, S.C., 2006. Population genetic structure of the Japanese eel Anguilla japonica in the northwest Pacific Ocean: evidence of non-panmictic populations. Mar. Ecol. Prog. Ser. 308, 221-230.

Tzeng, W.N., 1982. Newly record of the elver, Anguilla celebesensis Kaup, from Taiwan. Bioscience 19,57-66 (in Chinese with English abstract).

Tzeng, W.N., Tabeta, O., 1983. First record of the Short-finned eel Anguilla bicolor pacifica Elvers form Taiwan. Bull. Jap. Soc. Sci. Fish. 49 (1), 27-32.

Tzeng, W.N., 1984. An estimate of the exploitation rate of Anguilla japonica elvers immigrating into the coastal waters of Shuang-Chi River Taiwan. Bull. Inst. Zoo Acad. Sinica 23, 173-180.

Tzeng, W.N., 2006. Surface seawater temperature as a potential cause of delayed arrival of the Japanese eel Anguilla japonica elvers on the coast of Taiwan. J. Fish. Soc. Taiwan 33, 115-126.

Tzeng, W.N., Chang, C.W., 2001. Stock status and management prospect of freshwater eel Anguilla spp. in Taiwan. J. Taiwan Fish. Res. 9, 251-258.

Tzeng, W.N., Cheng, P.W., Lin, F.Y., 1995. Relative abundance, sex ratio and population structure of the Japanese eel Anguilla japonica in the Tanshui River system of northern Taiwan. J. Fish Biol. 46, 183-201.

Weeder, J.A., Uphoff, J.H.J., 2009. Are American eel harvest in Maryland's Chesapeake Bay sustainable? In: Casselman, J.M., Cairns, D.K. (Eds.), Eels at the Edge: Science, Status and Conservation Concerns. Proceedings of the International Eel Symposium. Québec City, Québec, Canada. Am. Fish. Soc. Sym. 58, 347-358. 